\title{
Nodal promotes glioblastoma cell growth
}

\section{Tanya De Silva, Gang Ye, Yao-Yun Liang, Guodong Fu, Guoxiong $\mathrm{Xu}^{\dagger}$ and Chun Peng*}

Department of Biology, York University, Toronto, ON, Canada

\section{Edited by:}

Michael O'Connor, University of

Minnesota, USA

Reviewed by:

Anna Petryk, University of Minnesota, USA

Osamu Shimmi, University of

Helsinki, Finland

S. Newfeld, Arizona State University, USA

\section{*Correspondence:}

Chun Peng, Department of Biology, York University, 4700 Keele Street,

Toronto, ON, Canada M3J 1 P3.

e-mail: cpeng@yorku.ca

${ }^{\dagger}$ Present address:

Guoxiong Xu, Jinshan Hospital, Fudan University, Shanghai, China.
Nodal is a member of the transforming growth factor- $\beta$ (TGF- $\beta$ ) superfamily that plays critical roles during embryogenesis. Recent studies in ovarian, breast, prostate, and skin cancer cells suggest that Nodal also regulates cell proliferation, apoptosis, and invasion in cancer cells. However, it appears to exert both tumor-suppressing and tumor-promoting effects, depending on the cell type. To further understand the role of Nodal in tumorigenesis, we examined the effect of Nodal in glioblastoma cell growth and spheroid formation using U87 cell line. Treatment of U87 with recombinant Nodal significantly increased U87 cell growth. In U87 cells stably transfected with the plasmid encoding Nodal, Smad2 phosphorylation was strongly induced and cell growth was significantly enhanced. Overexpression of Nodal also resulted in tight spheroid formation. On the other hand, the cells stably transfected with Nodal siRNA formed loose spheroids. Nodal is known to signal through activin receptor-like kinase 4 (ALK4) and ALK7 and the Smad2/3 pathway. To determine which receptor and Smad mediate the growth promoting effect of Nodal, we transfected siRNAs targeting ALK4, ALK7, Smad2, or Smad3 into Nodal-overexpressing cells and observed that cell growth was significantly inhibited by ALK4, ALK7, and Smad3 siRNAs. Taken together, these findings suggest that Nodal may have tumor-promoting effects on glioblastoma cells and these effects are mediated by ALK4, ALK7, and Smad3.

Keywords: Nodal, ALK4, ALK7, glioblastoma

\section{INTRODUCTION}

Nodal, one of the transforming growth factor- $\beta$ (TGF- $\beta$ ) superfamily members, was originally discovered in genetic studies as a gene essential for the primitive streak formation and maintenance in mouse embryos (Conlon et al., 1994). Subsequent studies demonstrate that Nodal plays an essential role in driving diverse embryological fates, including the formation of mesoderm and endoderm, specification of body axis, as well as self-renewal and differentiation (Weng and Stemple, 2003; Shen, 2007). Similar to other members of the TGF- $\beta$ superfamily, Nodal signals through serine/threonine receptors kinases. Two type I receptors, activin receptor-like kinase 4 (ALK4) and ALK7, and two type II Activin receptors (ActRIIA and ActRIIB) are known to mediate Nodal signaling (Wang and Tsang, 2007). In addition, Cripto acts as a co-receptor for Nodal. Activation of the receptors by Nodal leads to the phosphorylation of Smad2/3 which further bind to Smad4 and translocate into the nucleus, where a variety of genes are transcriptionally regulated by the complexes (Schier, 2009).

Previously, we reported that Nodal is expressed in ovarian cancer cell lines and that overexpression of Nodal inhibited ovarian cancer cell proliferation (Xu et al., 2004). We also found that Nodal induced ovarian cancer cell apoptosis (Xu et al., 2006; Ye et al., 2011). Furthermore, we showed that Nodal inhibited cell proliferation by inducing the expression and by inhibiting the degradation of a growth inhibitory gene, cyclin G2 (Xu et al., 2008; Fu and Peng, 2011). The growth inhibitory effect of Nodal has also been observed in breast cancer cell lines (Zhong et al., 2009) and in some prostate cancer cell lines (Vo and Khan, 2011). However, several studies also reported that Nodal has tumorigenic effects. For example, Nodal has been shown to promote melanoma progression (Topczewska et al., 2006). These findings suggest that Nodal may have both tumor-suppressing and tumor-promoting effects, depending on the cell type and/or the cellular environment of the target organs.

Since TGF- $\beta$ has been reported to inhibit the growth of glioblastma cell lines (Piek et al., 1999) and ALK7 is highly expressed in the adult brain (Ryden et al., 1996; Tsuchida et al., 1996), we investigated the effect of Nodal on U87 glioblastma cells. Glioblastma cells in culture have the ability to form spheroids or adherent growth (Witusik-Perkowska et al., 2011), therefore, we used cell growth and spheroid formation assays, along with overexpression and gene silencing approaches, to determine the effect and signaling pathway of Nodal in U87 cells. We demonstrate that Nodal promotes cell growth and spheroid formation in U87 cells through ALK4, ALK7, and Smad3.

\section{MATERIALS AND METHODS CELL LINES AND CELL CULTURE}

U87 cell line was obtained from American Type Culture Collection (Rockville, MD, USA). The cells were cultured in Dulbecco's modified Eagle's medium (DMEM, Hyclone, Logan, UT, USA) supplemented with $100 \mathrm{IU} / \mathrm{ml}$ penicillin and $100 \mu \mathrm{g} / \mathrm{ml}$ streptomycin (Invitrogen Canada, Inc., Burlington, ON, USA) in the presence of $10 \%$ fetal bovine serum (FBS, Sigma). Human ovarian cancer cell lines (OV2008) expressing Nodal or its control vector were generated and cultured as previously reported (Ye et al., 2011). 


\section{GENERATION OF NODAL AND ShNODAL STABLE CELL LINES}

To generate Nodal-overexpressing cells, full-length Nodal coding sequence was cloned into mammalian expression vector pcDNA3.1/V5-His (Invitrogen), followed by Lipofectamine transfection into U87 cells. Stable cells were selected using $0.5 \mu \mathrm{g} / \mathrm{ml}$ of neomycin, which was initiated $24 \mathrm{~h}$ after transfection. Small hairpin sequence targeting human Nodal (shNodal; $5^{\prime}$ CCGGGCGGTTTCAGATGGACCTATTCTCGAGAATAGGTCC ATCTGAAACCGCTTTTTG-3') was cloned into the pSUPER retroviral vector (Oligoengine, Seattle, WA, USA). To produce shNodal-expressing retroviruses, 293T cells were plated at $10^{6}$ cells/60-mm-diameter tissue culture dishes and transfected with the pSUPER (without insert or containing shNodal) and pCL retroviral packaging vector by the calcium phosphate method. At $20 \mathrm{~h}$ post-transfection, the medium was replaced with fresh DMEM containing 10\% FBS and cells were grown for an additional $24 \mathrm{~h}$. The conditioned medium containing recombinant retroviruses was collected by syringe and filtered through $0.45 \mu \mathrm{m}$ pore-size polysulfonic filters. The supernatants were mixed with $6 \mu \mathrm{g} / \mathrm{ml}$ of polybrene (Sigma) and applied immediately to U87 and U87-Nodal cells. At $24 \mathrm{~h}$ after infection, cells were selected using $2 \mu \mathrm{g} / \mathrm{ml}$ of puromycin (Invitrogen).

\section{TRANSIENT TRANSFECTION OF ALK7 AND ALK4 siRNAs}

Transient transfections were carried out using lipofectamine 2000 (Invitrogen). Briefly, $200 \mathrm{nM}$ siRNAs (siALK4, siALK7, siSmad2, siSmad3, or negative control (NC) siRNA (GenePharma, Shanghai, China) and lipofectamine 2000 were incubated with OPTI MEM1 medium (OMEM, Invitrogen) at room temperature for $20 \mathrm{~min}$. The mixture was then added to the cells. After $6 \mathrm{~h}$ incubation, the OMEM was replaced by normal cultured medium supplemented with $10 \%$ FBS. Cells were allowed to recover for $24 \mathrm{~h}$ prior to cell growth assays. The sequences of NC, siALK7 and siALK4 and confirmation of their efficiency have been reported (Nadeem et al., 2011). Smad2 siRNA (sense GUCCCAUGAAAAGACUUAATT, and anti-sense UUAAGUCUUUUCAUGGGACUU; Pannu et al., 2007) and Smad3 siRNA (sense CUGUGUGAGUUCGCCUUCAUU and anti-sense UGAAGGCGAACUCACACAGUU; Kobayashi et al., 2006) sequences were taken from publications.

\section{DETERMINATION OF CELL GROWTH}

Cell growth was determined by manual cell counting. U87 cells were cultured in 24 well culture plates at a cell density of $2 \times 10^{5}$ cells/well. Cells were treated with recombinant proteins for $48 \mathrm{~h}(10 \mathrm{ng} / \mathrm{ml} \mathrm{TGF}-\beta 1$, and $100 \mathrm{ng} / \mathrm{ml}$ or $500 \mathrm{ng} / \mathrm{ml}$ Nodal, R\&D systems, Minneapolis). Stable cells expressing Nodal or shNodal were plated at the density of $1 \times 10^{5}$ and cultured for 2 days. At the end of each experiment, cells were trypsinized and cell number was determined by trypan blue exclusion assay.

\section{PROTEIN EXTRACTION AND WESTERN BLOT ANALYSES}

U87 stable cells cultured in $6 \mathrm{~cm}$ dishes were washed twice with icecold PBS and lysed with RIPA buffer (50 mM Tris-HCl, $150 \mathrm{mM}$ $\mathrm{NaCl}, 1 \%$ Triton X-100, 0.5\% deoxycholate and 1\% SDS) containing complete protease inhibitor cocktail. Protein concentrations were determined by Bradford assay and equal amount of proteins were subjected to SDS-PAGE and blotted onto a PVDF membrane. The membrane was blocked with TBST [10 mM Tris- $\mathrm{HCl}(\mathrm{pH}$ 8.0), $150 \mathrm{mM} \mathrm{NaCl}$, and $0.05 \%$ Tween 20] containing 5\% non-fat dry milk powder at room temperature for $60 \mathrm{~min}$. The membrane was then incubated overnight at $4^{\circ} \mathrm{C}$ with a rabbit anti-Nodal antibody developed in our lab (1:1000), or phospho Smad2, Smad2/3 (Cell Signaling, 1:1000), and $\beta$-actin (Sigma, 1:5000) prepared in TBST with 5\% BSA. The membranes were then washed three times with TBST and incubated for $1 \mathrm{~h}$ with a horseradish peroxidase conjugated secondary antibody (1:5000 dilutions). After washing as described above, the bound antibodies were detected using an enhanced chemiluminescence (ECL) kit (GE Healthcare, Quebec) according to instructions from the manufacturer.

\section{SPHEROID FORMATION ASSAYS}

Hanging drop cultures were performed by placing $20 \mu \mathrm{l}$ drops ( 5000 cells/drop) of U87 cells onto the inner surface of lids of $100 \mathrm{~mm}$ culture dishes. The covers were then inverted and placed on a dish containing $15 \mathrm{ml}$ of PBS. Plates were incubated for 4 days to allow the formation of spheroids. At the end of each experiment, spheroids were examined and photographed using a phase contrast microscope. Spheroid area was measured with image J.

\section{STATISTIC ANALYSIS}

Results are expressed as the mean \pm SEM. Student's $t$-test was used to determine the differences between groups. Statistical significance was defined as $P<0.05$.

\section{RESULTS}

\section{NODAL ENHANCED THE GROWTH OF U87 CELLS}

To test the effect of Nodal on U87 cell growth, cells were treated with recombinant Nodal or TGF- $\beta 1$ for $48 \mathrm{~h}$. Treatment with low dose of Nodal did not change cell number but higher dose of Nodal significantly increased cell numbers. In contrast, TGF- $\beta 1$ significantly reduced the number of U87 cells (Figure 1).

To further investigate the effect of Nodal on U87 cells, four stable cell lines including control (U87-EV), Nodal shRNA (U87shNodal), Nodal-overexpressing (U87-Nodal), and Nodal plus Nodal shRNA (U87-Nodal/shNodal) were generated. As shown in Figure 2A, the U87-Nodal cells showed strong overexpression of Nodal. In the U87-Nodal cells co-expressing shNodal, Nodal expression level was reduced but Nodal level was still much higher than the control cells. In control U87 cells stably transfected with shNodal, there was a decrease in Nodal expression levels (Figure 2A). To confirm that Nodal overexpression leads to the activation of its signaling pathways, we measured phosphor-Smad2 levels in these cell lines. In U87-Nodal cells, Smad2 phosphorylation was strongly induced. Smad2 activation was also observed in U87-Nodal/shNodal cells, although to a lesser extent (Figure 2A). In cell growth assays, U87-Nodal cells grew significantly faster than the control cells and this effect was slightly, but significantly reduced by the co-transfection of shNodal (Figure 2B). We have demonstrated that Nodal reduced proliferation and induced apoptosis in an ovarian cancer cell line, OV2008 (Xu et al., 2004; Ye et al., 2011). Here, we compared the effect of Nodal on cell growth between OV2008 and U87 cells. Overexpression of Nodal in OV2008 decreased cell density; however, 

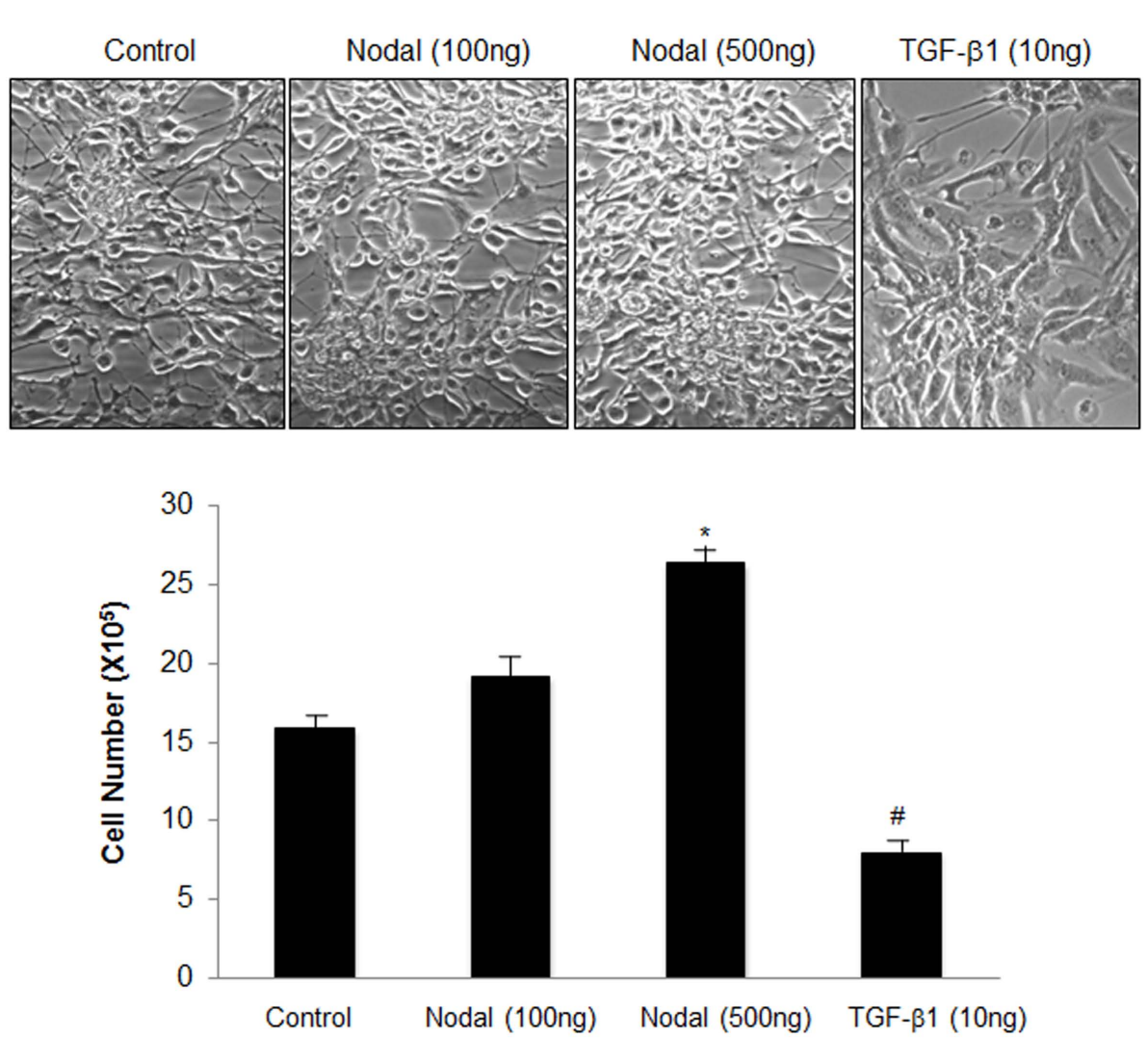

FIGURE 1 | Effects of Nodal and TGF- $\beta 1$ onglioblastoma cell growth. U87 cells cultured in 24 well plates were treated with either recombinant Nodal (100 or $500 \mathrm{ng} / \mathrm{ml}$ ) or TGF- $\beta 1(10 \mathrm{ng} / \mathrm{ml})$ for $48 \mathrm{~h}$. Cell numbers were determined by trypan blue exclusion.
Representative cell images and summary graph are shown. Data represent mean $\pm \operatorname{SEM}(n=3)$. The experiment was repeated three times with similar results. ${ }^{*} P<0.05$ vs. control, ${ }^{\#} P<0.05$ vs. all other groups. the opposite effect was observed when Nodal was overexpressed in U87 cells (Figure 2C).

\section{EFFECTS OF NODAL ON SPHEROID FORMATION}

Hanging drop technique was used to examine the role of Nodal in spheroid formation of U87 cells. As shown in Figure 3A, Nodal stable cells exhibited an enhanced ability to form tight and dense spheroid compared with control. The spheroid structure was totally disintegrated in U87-shNodal cells, showing a loose and uneven cell aggregate and the cell distribution area is much larger than that of other cells (Figure 3B). Although tight structure was still seen in U87-Nodal/shNodal cells, the cell density was lower and the spheroid area was slightly bigger, when compared to U87-Nodal cells.

\section{NODAL ENHANCED U87 GROWTH BY ACTING THROUGH ALK4, ALK7, AND Smad3}

Since Nodal signaling is mainly mediated by ALK4 and ALK7 and the Smad pathway, we next examined the contribution of these receptors to the growth promoting effects of Nodal in U87 cells. We transfected siRNAs targeting either ALK4 or ALK7 into the U87-Nodal cells and found that both of the siRNAs significantly decreased cell numbers (Figure 4A). Since Smad2 and Smad3 are downstream mediators of ALK4/7, we also determined their involvement in Nodal-regulated cell growth. As shown in Figure 4B, knockdown of Smad3 significantly suppressed cell growth. However, knockdown of Smad2 only slightly decreased cell numbers.

\section{DISCUSSION}

The role of Nodal in cancer cell biology has been previously examined in several cancer cell lines and yields paradoxical findings. Previous studies in our lab have demonstrated that Nodal signals through ALK7 receptor to inhibit proliferation and to induce apoptosis in ovarian cancer cell lines (Xu et al., 2004, 2006) and breast cancer cell lines (Zhong et al., 2009). Interestingly, Nodal was reported to be only expressed in aggressive melanomas, but not in normal skin cells and inhibition of Nodal promoted tumor regression (Topczewska et al., 2006). Recent studies in prostate cancer cell lines showed that Nodal has differential effects on different cell lines. For example, Nodal inhibited proliferation in WPE, RWPE1, and DU145 cells. While it had no effect on PC3 cells proliferation, it promoted migrations in these cells (Vo and Khan, 2011). On the other hand, Nodal enhanced the proliferation of LNCaP cells and are expressed in malignant prostate cancer cells but not in benign tumors (Lawrence et al., 2011). In this study, we found that treatment with recombinant Nodal or stable transfection of a Nodal expression construct into U87 cells promoted cell growth, 
A

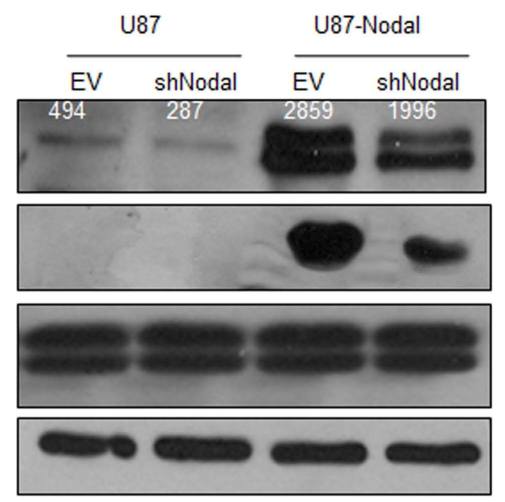

B

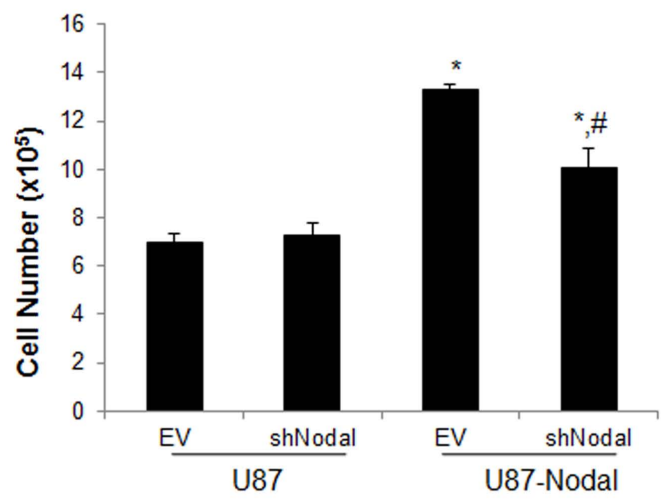

C

OV2008
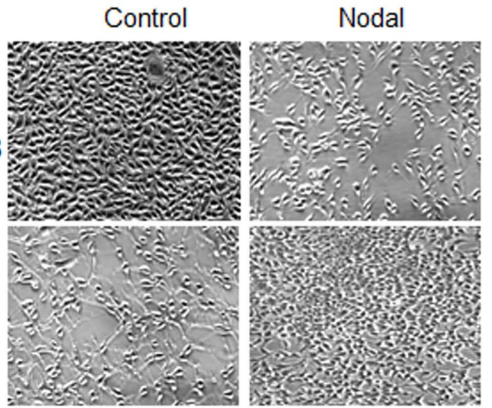

FIGURE 2 | Effect of Nodal overexpression and knockdown on glioblastoma cell proliferation. (A) Four cell lines, U87 transfected with a control empty vector (U87-EV), U87 transfected with Nodal shRNA (U87-shNodal), U87 transfected with Nodal plasmid (U87-Nodal), and 87 transfected with both Nodal expression plasmid and Nodal shRNA (U87-Nodal/shNodal) were generated. Proteins extracted from these cell lines were analyzed by Western blotting using antibodies against Nodal, phosphor-Smad2 (pSmad2), total Smad2 and Smad3 (Smad2/3), and $\beta$-actin as the loading control. Overexpression and activation of Smad2 were confirmed in the U87-Nodal cells. Numbers on the Nodal blot are densitometry readings of the bands. (B) Cell growth assays. The stable cell lines were cultured for $48 \mathrm{~h}$ and cell numbers were determined by the trypan blue exclusion method. Data represents mean $\pm \operatorname{SEM}(n=3)$. The experiment was done three times and similar results were obtained. ${ }^{*} P<0.01$ vs. U87-EV and U87-shNodal, ${ }^{*} P<0.05$ vs. U87-EV and U87-Nodal. (C) Comparison of the effect of Nodal overexpression in U87 and OV2008 cells. Two pairs of cell lines, control and Nodal-overexpressing OV2008 and control and Nodal-overexpressing U87 cells, were cultured for 2 days before pictures were taken.

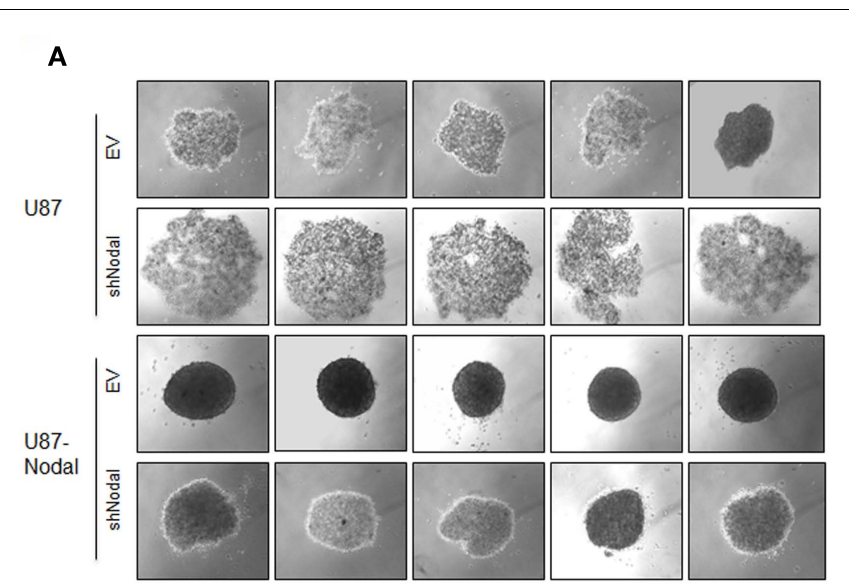

B

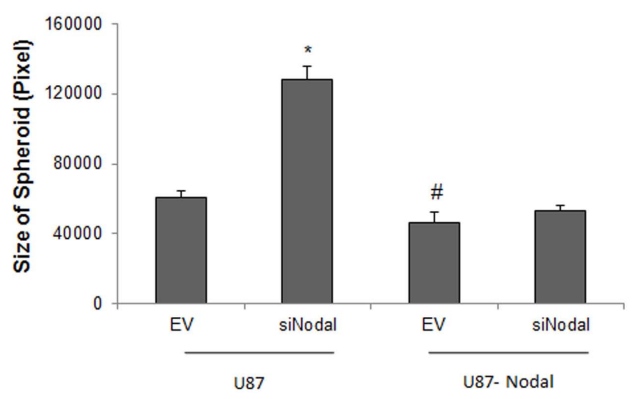

FIGURE 3 | Nodal enhanced spheroid formation. U87 cells stably transfected with Nodal and/or Nodal shRNA were cultured in hanging drops and formation of spheroids was observed at the forth day after culture. (A) Photographs of representative spheroids from each cell lines. (B) Quantifications of spheroid area. Data represent mean \pm SEM $(n>35$ each group), ${ }^{*} P<0.001$ vs. the other groups. This experiment was performed three times with similar results.

in contrast to what we observed previously in ovarian cancer cells. These findings further suggest that Nodal is capable of exerting both tumor-promoting and tumor-suppressing effects.

In this study, the long-term effects of Nodal gain-of-function and loss-of-function phenotypes were examined by generating stable cell lines overexpressing Nodal and/or Nodal siRNA in human U87 glioblastoma cells. The overexpressing and knockdown effects were validated by Western blots. We demonstrated that overexpression of Nodal induced a significant increase in cell numbers when compared to the control. Smad2 phosphorylation was strongly activated in Nodal-overexpressing cells, confirming that the activation of Nodal signaling pathway in these cells. The growth promoting effect of Nodal was partially reversed by co-expression of Nodal siRNA, indicating that the higher cell number in Nodal-overexpressing cells is indeed due to Nodal overexpression.

Since three dimensional tumor cell cultures like spheroid formation closely resembles the tumor cell microenvironment (Sodek et al., 2009), we examined the effect of Nodal on spheroid formation in U87 cells. Overexpression of Nodal induced the formation of solid and compact spheroids with tightly packaged and uniform structures. Remarkably, silencing of Nodal expression using siRNA resulted in the formation of loose spheroids with disintegrated and 


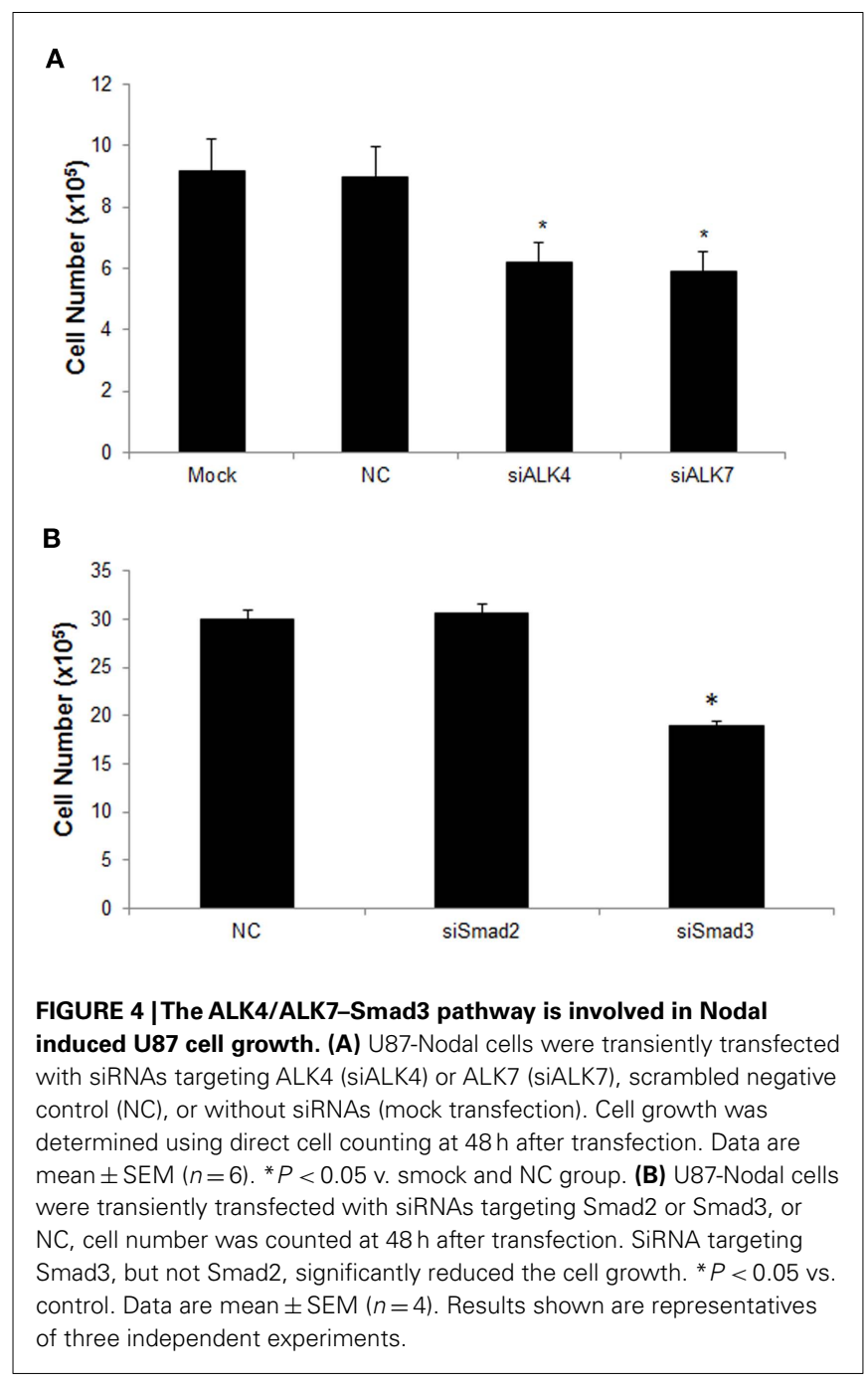

irregular structures in control cells. In Nodal-overexpressing cells, Nodal siRNA also partially reversed the effect of Nodal on spheroid formation. Since compact spheroid formation has been suggested to correlate with aggressiveness of tumors (Sodek et al., 2009), these results suggest that Nodal has tumor-promoting effects in U87 cells.

The tumorigenic effect by Nodal in U87 cells has also been recently reported (Lee et al., 2010). In agreement with our results,

\section{REFERENCES}

Conlon, F. L., Lyons, K. M., Takaesu, N., Barth, K. S., Kispert, A., Herrmann, B., and Robertson, E. J. (1994). A primary requirement for nodal in the formation and maintenance of the primitive streak in the mouse. Development 120 , 1919-1928.

Derynck, R., Akhurst, R. J., and Balmain, A. (2001). TGF-beta signaling in tumor suppression and cancer progression. Nat. Genet. 29, 117-129.

Fu, G., and Peng, C. (2011). Nodal enhances the activity of FoxO3a

Lee et al. (2010) showed that overexpression of Nodal increased MMP-2 secretion, enhanced cell invasiveness and promoted cell proliferation in vitro, as well as increased tumor growth in vivo. Conversely, the knockdown of Nodal expression resulted in the opposite phenomena (Lee et al., 2010). A subsequent report indicated that Nodal stimulates angiogenesis in U87 glioblastoma cells and ERK1/2-HIF-1a signaling pathway is involved in this process (Hueng et al., 2011).

Both ALK4 and ALK7 have been reported to mediate Nodal signaling (Reissmann et al., 2001). It has been reported that Nodal promotes the tumorigenicity and plasticity of metastatic melanoma in part by activating ALK4 receptor associated with crypto-1 and knockdown of Nodal stimulated tumor differentiation and regression (Topczewska et al., 2006; Strizzi et al., 2009). Using siRNAs to silence the expression of ALK4 and ALK7, we demonstrated that not only ALK4 but also ALK7 signaling pathway is involved in Nodal-stimulated glioblastoma cell growth. ALK7 has been reported to inhibit proliferation (Xu et al., 2004; Zhong et al., 2009) and to induce apoptosis (Kim et al., 2004; Munir et al., 2004; Xu et al., 2004, 2006; Zhang et al., 2008; Ye et al., 2011) in various cells lines. This study shows that ALK7 also has growth promoting effects on some cancer cells. Similarly, gene silencing techniques revealed that $S$ mad 3 mediates the growth promoting effect of Nodal.

Although both TGF- $\beta$ and Nodal activate the Smad2/3 pathway (Graham and Peng, 2006), they have differential effects on U87 cell growth. Treatment with Nodal enhanced, whereas treatment with TGF- $\beta$ decreased, U87 cell growth. This finding suggests that other signaling pathways may be differentially activated by TGF- $\beta$ and Nodal, which could interact with the Smad pathway to differentially regulate gene expression. The complexity of TGF$\beta$ signaling in cancer progression is well documented with both tumor-suppressing and tumor-promoting effects (Derynck et al., 2001). Although the mechanism underlying the differential effects of Nodal on different cancer cells remains to be investigated, it is possible that the role of Nodal in tumorigenesis is dependent on cellular microenvironment, the type of cancer, and/or the stage of tumor development.

\section{ACKNOWLEDGMENTS}

This study was supported by a grant from Canadian Institutes of Health Research (CIHR MOP-89931) to Chun Peng. Chun Peng was a recipient of a mid-career award from CIHR and Ontario Women's Health Council.

human gliomas. J. Neurooncol. 104, 21-31.

Kim, B. C., Van Gelder, H., Kim, T. A., Lee, H. J., Baik, K. G., Chun, H. H., Lee, D. A., Choi, K. S., and Kim, S. J. (2004). Activin receptor-like kinase-7 induces apoptosis through activation of MAPKs in a Smad3-dependent mechanism in hepatoma cells. J. Biol. Chem. 279, 28458-28465.

Kobayashi, T., Liu, X., Wen, F. Q., Kohyama, T., Shen, L., Wang, X. Q., Hashimoto, M., Mao, L., Togo, S., Kawasaki, S., Sugiura, H., Kamio, K., and Rennard, S. I. (2006). Smad3 mediates TGF-betal-induced collagen gel contraction by human lung fibroblasts. Biochem. Biophys. Res. Commun. 339, 290-295.

Lawrence, M. G., Margaryan, N. V., Loessner, D., Collins, A., Kerr, K. M., Turner, M., Seftor, E. A., Stephens, C. R., Lai, J., Postovit, L. M., Clements, J. A., and Hendrix, M. J. (2011). Reactivation of embryonic nodal signaling is associated with tumor progression and promotes the growth of prostate cancer cells. Prostate 71, 1198-1209. 
Lee, C. C., Jan, H. J., Lai, J. H., Ma, H. I., Hueng, D. Y., Lee, Y. C., Cheng, Y. Y., Liu, L. W., Wei, H. W., and Lee, H. M. (2010). Nodal promotes growth and invasion in human gliomas. Oncogene 29, 3110-3123.

Munir, S., Xu, G., Wu, Y., Yang, B., Lala, P. K., and Peng, C. (2004). Nodal and ALK7 inhibit proliferation and induce apoptosis in human trophoblast cells. J. Biol. Chem. 279, 31277-31286.

Nadeem, L., Munir, S., Fu, G., Dunk, C., Baczyk, D., Caniggia, I., Lye, S., and Peng, C. (2011). Nodal signals through activin receptor-like kinase 7 to inhibit trophoblast migration and invasion: implication in the pathogenesis of preeclampsia. Am. J. Pathol. 178, 1177-1189.

Pannu, J., Nakerakanti, S., Smith, E., Ten Dijke, P., and Trojanowska, M. (2007). Transforming growth factorbeta receptor type I-dependent fibrogenic gene program is mediated via activation of Smadl and ERK1/2 pathways. J. Biol. Chem. 282, 10405-10413.

Piek, E., Westermark, U., Kastemar, M., Heldin, C. H., Van Zoelen, E. J., Nister, M., and Ten Dijke, P. (1999). Expression of transforminggrowth-factor (TGF)-beta receptors and Smad proteins in glioblastoma cell lines with distinct responses to TGF-betal. Int. J. Cancer 80, 756-763.

Reissmann, E., Jornvall, H., Blokzijl, A., Andersson, O., Chang, C., Minchiotti, G., Persico, M. G., Ibanez, C. F., and Brivanlou, A. H. (2001). The orphan receptor ALK7 and the Activin receptor ALK4 mediate signaling by Nodal proteins during vertebrate development. Genes Dev. 15, 2010-2022.
Ryden, M., Imamura, T., Jornvall, H., Belluardo, N., Neveu, I., Trupp, M., Okadome, T., Ten Dijke, P., and Ibanez, C. F. (1996). A novel type I receptor serine-threonine kinase predominantly expressed in the adult central nervous system. J. Biol. Chem. 271, 30603-30609.

Schier, A. F. (2009). Nodal morphogens. Cold Spring Harb. Perspect. Biol. 1, a003459.

Shen, M. M. (2007). Nodal signaling: developmental roles and regulation. Development 134, 1023-1034.

Sodek, K. L., Ringuette, M. J., and Brown, T. J. (2009). Compact spheroid formation by ovarian cancer cells is associated with contractile behavior and an invasive phenotype. Int. J. Cancer 124, 2060-2070.

Strizzi, L., Postovit, L. M., Margaryan, N. V., Lipavsky, A., Gadiot, J., Blank, C., Seftor, R. E., Seftor, E. A., and Hendrix, M. J. (2009). Nodal as a biomarker for melanoma progression and a new therapeutic target for clinical intervention. Expert Rev. Dermatol. 4, 67-78.

Topczewska, J. M., Postovit, L. M., Margaryan, N. V., Sam, A., Hess, A. R., Wheaton, W. W., Nickoloff, B. J., Topczewski, J., and Hendrix, M. J. (2006). Embryonic and tumorigenic pathways converge via Nodal signaling: role in melanoma aggressiveness. Nat. Med. 12, 925-932.

Tsuchida, K., Sawchenko, P. E., Nishikawa, S., and Vale, W. W. (1996). Molecular cloning of a novel type I receptor serine/threonine kinase for the TGF beta superfamily from rat brain. Mol. Cell. Neurosci. 7, 467-478.

Vo, B. T., and Khan, S. A. (2011). Expression of nodal and nodal receptors in prostate stem cells and prostate cancer cells: autocrine effects on cell proliferation and migration. Prostate 71, 1084-1096.

Wang, H., and Tsang, B. K. (2007) Nodal signalling and apoptosis. Reproduction 133, 847-853.

Weng, W., and Stemple, D. L. (2003). Nodal signaling and vertebrate germ layer formation. Birth Defects Res. C Embryo Today 69, 325-332.

Witusik-Perkowska, M., Rieske, P. Hulas-Bigoszewska, K., Zakrzewska, M., Stawski, R., Kulczycka-Wojdala, D., Bienkowski, M., Stoczynska-Fidelus, E., Gresner, S. M., Piaskowski, S., Jaskolski, D. J., Papierz, W. Zakrzewski, K., Kolasa, M., Ironside, J. W., and Liberski, P. P. (2011). Glioblastoma-derived spheroid cultures as an experimental model for analysis of EGFR anomalies. J. Neurooncol. 102, 395-407.

Xu, G., Bernaudo, S., Fu, G., Lee, D. Y., Yang, B. B., and Peng, C. (2008). Cyclin G2 is degraded through the ubiquitin-proteasome pathway and mediates the antiproliferative effect of activin receptor-like kinase 7. $\mathrm{Mol}$. Biol. Cell 19, 4968-4979.

Xu, G., Zhong, Y., Munir, S., Yang, B. B., Tsang, B. K., and Peng, C. (2004). Nodal induces apoptosis and inhibits proliferation in human epithelial ovarian cancer cells via activin receptor-like kinase 7 . J. Clin. Endocrinol. Metab. 89, 5523-5534.

Xu, G., Zhou, H., Wang, Q., Auersperg, N., and Peng, C. (2006). Activin receptor-like kinase 7 induces apoptosis through up-regulation of Bax and down-regulation of Xiap in normal and malignant ovarian epithelial cell lines. Mol. Cancer Res. 4, 235-246.

Ye, G., Fu, G., Cui, S., Zhao, S., Bernaudo, S., Bai, Y., Ding, Y., Zhang, Y.,
Yang, B. B., and Peng, C. (2011). MicroRNA 376c enhances ovarian cancer cell survival by targeting activin receptor-like kinase 7 : implications for chemoresistance. J. Cell Sci. 124, 359-368.

Zhang, Y. Q., Sterling, L., Stotland, A., Hua, H., Kritzik, M., and Sarvetnick, N. (2008). Nodal and lefty signaling regulates the growth of pancreatic cells. Dev. Dyn. 237, 1255-1267.

Zhong, Y., Xu, G., Ye, G., Lee, D., Modica-Amore, J., and Peng, C. (2009). Nodal and activin receptorlike kinase 7 induce apoptosis in human breast cancer cell lines: role of caspase 3. Int. J. Physiol. Pathophysiol. Pharmacol. 1, 83-96.

Conflict of Interest Statement: The authors declare that the research was conducted in the absence of any commercial or financial relationships that could be construed as a potential conflict of interest.

Received: 04 October 2011; accepted: 11 April 2012; published online: 25 April 2012.

Citation: De Silva $T$, Ye G, Liang $Y-Y, \quad F u \quad G, \quad X u \quad G$ and Peng $C$ (2012) Nodal promotes glioblastoma cell growth. Front. Endocrin. 3:59. doi: 10.3389/fendo.2012.00059

This article was submitted to Frontiers in Experimental Endocrinology, a specialty of Frontiers in Endocrinology. Copyright (c) 2012 De Silva, Ye, Liang, $F u, X u$ and Peng. This is an open-access article distributed under the terms of the Creative Commons Attribution Non Commercial License, which permits noncommercial use, distribution, and reproduction in other forums, provided the original authors and source are credited. 